EXPERIMENTAL STUDY

\title{
Origin of parathyroid hormone (PTH) fragments detected by intact-PTH assays
}

\author{
L Nguyen-Yamamoto, L Rousseau, J-H Brossard, R Lepage ${ }^{1}$, P Gao ${ }^{2}$, T Cantor ${ }^{2}$ and P D’Amour \\ Centre de recherche, Centre hospitalier de l'Université de Montréal-Hôpital Saint-Luc and ${ }^{1}$ Departments of Medicine and Biochemistry. \\ Université de Montréal, Montréal, Québec, Canada, and ${ }^{2}$ Scantibodies Laboratory Inc., Santee, California, USA
}

(Correspondence should be addressed to P D’Amour, Centre de recherche-CHUM-Hôpital Saint-Luc, 264 René Lévesque Blvd, East, Montréal, Québec H2X 1P1 Canada; Email: rechcalcium.chum@ssss.gouv.qc.ca)

\begin{abstract}
Background: Intact parathyroid hormone (I-PTH) assays react with non-(1-84)PTH, large carboxylterminal $(\mathrm{C})$ fragments with a partially preserved amino-terminal $(\mathrm{N})$ structure. They account for up to $50 \%$ of I-PTH in renal failure and may be implicated in PTH resistance. We wanted to know if they were secreted by the parathyroid glands and generated by peripheral metabolism of PTH(1-84). Methods: Anesthetized normal and nephrectomized (NPX) rats were injected i.v. with $1.5 \mu \mathrm{g}$ human (h) PTH(1-84). Blood was obtained from 8 rats at 2, 4, 6, 8, 12, 24, 48 and 96 min. I-PTH (Allegro IPTH) was measured in all samples. Pools of serum were fractionated by HPLC at each time point and the fractions assayed to quantitate hPTH(1-84) and non-(1-84)PTH. Secretion studies were performed with dispersed cells from 5 parathyroid adenomas. The serum of 10 patients with primary hyperparathyroidism and cell supernatants were fractionated by HPLC and were analyzed as described.

Results: hPTH(1-84) disappeared from serum biexponentially. The half-life of the first exponential was similar in normal $(2.08 \mathrm{~min})$ and NPX (1.94 min) rats, while that of the second was longer in NPX rats (32.4 vs $20.9 \mathrm{~min})$. The residual quantity of $\mathrm{hPTH}(1-84)$ under the curve was greater in NPX $(6964 \pm 2392 \mathrm{pmol})$ than in normal rats $(3229 \pm 561 \mathrm{pmol} ; P<0.001)$. Non-(1-84)PTH concentration was maximal at $8 \mathrm{~min}$ in both groups and was higher in NPX $(92.8 \pm 13.8 \mathrm{pmol} / \mathrm{l})$ than in normal rats $(38.8 \pm 7.2 \mathrm{pmol} / \mathrm{l} ; P<0.01)$. The area under the curve of non-(1-84)PTH was also greater in NPX (1904 $\pm 405 \mathrm{pmol})$ than in normal rats $(664 \pm 168 \mathrm{pmol} ; P<0.001)$. All parathyroid adenomas secreted non-(1-84)PTH. It represented $21.1 \pm 3.9 \%$ of secreted and $32.5 \pm 1.3 \%$ of circulating I-PTH in primary hyperparathyroidism.

Conclusions: Non-(1-84)PTH, like other C-PTH fragments, originates from both the peripheral metabolism of hPTH(1-84) and from parathyroid gland secretion. Renal failure influences its concentration by increasing the amount of substrate available and by reducing non-(1-84)PTH clearance. Its higher proportion in serum relative to cell supernatants in primary hyperparathyroidism reflects the added role of peripheral metabolism and the longer half-life of fragments.
\end{abstract}

European Journal of Endocrinology 147 123-131

\section{Introduction}

The existence of circulating carboxyl-terminal (C) fragment(s) of parathyroid hormone (PTH) with a partially preserved amino-terminal $(\mathrm{N})$ structure is a relatively recent finding (1-3). These fragments are of particular interest because, at least theoretically, they could interact with the classic PTH/PTH related peptide receptor to modify some aspects of PTH(1-84) bioactivity. They were first identified by analyzing HPLC-fractionated sera with Nichol's intact PTH (I-PTH) radioimmunometric assay (1). This assay and other similar assays do not react with human (h) PTH(1-34) or C-fragments without a partially preserved N-structure $(4,5)$ but they do react with $\mathrm{hPTH}(7-84)$, a prototype of these circulating C-fragments $(1-3)$. Such is the case because most antisera raised against N-PTH have their epitopes in region 15-34 of the PTH structure (6). These fragments behave like other C-PTH fragments. Their concentration relative to that of $\mathrm{hPTH}(1-84)$ increases in hypercalcemia and decreases in hypocalcemia $(1,2)$. They also accumulate in renal failure to account for $40-50 \%$ of I-PTH immunoreactivity while representing only $15-20 \%$ in normal subjects $(1-3)$. Recent data suggest that synthetic $\mathrm{hPTH}(7-84)$ alone decreases ionized calcium concentration in thyroparathyroidectomized rats $(7,8)$ and antagonizes the calcemic effect of hPTH(1-84) $(8,9)$ and hPTH(1-34) 
(8) in the same animals, raising the possibility that circulating C-fragments with a partially preserved $\mathrm{N}$-structure could do the same. This could implicate them in the PTH resistance of renal failure (7).

We were thus interested to see how these fragments were generated in vivo and how acute renal failure affected their concentration. We wanted to know if, like other C-PTH fragments, they had a dual origin from both peripheral metabolism $(9,10)$ and secretion by the parathyroid glands $(11-14)$. The data to be presented here suggest a similar origin and behavior to other C-PTH fragments.

\section{Materials and methods}

\section{Metabolism of hPTH(1-84) in normal and acutely nephrectomized rats}

Experimental protocol This study was performed in male Sprague-Dawley rats weighing 275-300g, under general anesthesia (Somnotol, $6 \mathrm{mg} / 100 \mathrm{~g}$ ). Half the rats were nephrectomized bilaterally via a posterior surgical approach prior to injection (NPX rats) while the other half was sham-operated without removal of the kidneys (normal rats). hPTH(1-84) (Bachem, Torrance, CA, USA) was dissolved in barbital buffer, $0.05 \mathrm{~mol} / \mathrm{l}, \mathrm{pH} 8.6$, containing $15 \%$ normal rat serum, at a concentration of $1.5 \mu \mathrm{g} / 500 \mu \mathrm{l}$, and $500 \mu \mathrm{l}$ were injected into a jugular vein. Four groups of 8 normal or NPX rats were studied at the following time points: group 1, 2 and 4 min; group 2, 6 and $8 \mathrm{~min}$; group 3, 12 and $24 \mathrm{~min}$; group 4, 48 and 96 min. Five hundred microliters blood were collected through a jugular vein at the first time point, a volume equal to the injection volume, and exsanguination was performed via the abdominal aorta at the second time point. Serum was stored at $-75^{\circ} \mathrm{C}$ in aliquots until processed further or analyzed. The protocol was approved by the Animal Care Committee of our center in compliance with the Canadian Council on Animal Care guidelines.

Processing and analysis of samples I-PTH was measured in serum samples from all groups by a commercial I-PTH radioimmunometric assay which is nonreactive to endogenous rat PTH (Allegro I-PTH, Nichol's Institute, San Juan Capistrano, CA, USA). This assay has been demonstrated to react in an equimolar fashion with hPTH(1-84) and hPTH(7-84) (2, $3)$. It also reacts with circulating $\mathrm{C}$-fragments having a partially preserved $\mathrm{N}$-structure, also called non-(184)PTH in prior publications $(2,3)$. A pool of serum from 8 rats of each group at each time point was extracted in Sep-Pak Plus $\mathrm{C}_{18 \mu}$ cartridges (Waters, Chromatographic Division, Wilford, MA, USA) (15) and eluted with $3 \mathrm{ml} 80 \%$ acetonitrile in $0.1 \%$ trifluoroacetic acid (TFA). Acetonitrile was evaporated, and the residual volume freeze-dried. The samples were reconstituted in $0.6 \mathrm{ml} 0.1 \%$ TFA for HPLC analysis. Each sample was loaded on the same $\mathrm{C}_{18 \mu}$ Bondapak analytical column of $3.9 \times 300 \mathrm{~mm}$ (Waters), and eluted with a non-continuous linear gradient of acetonitrile, 15 to $50 \%$ in $0.1 \%$ TFA, delivered at $1.5 \mathrm{ml} / \mathrm{min}$ for 65 min by BioRad Model 2700 HPLC (Richmond, CA, USA). Fractions $(1.5 \mathrm{ml})$ were collected in polypropylene tubes precoated with $0.1 \%$ BSA in water. The acetonitrile present in each fraction was evaporated and the residual volume freeze-dried. Each fraction was reconstituted to $1 \mathrm{ml}$ with $0.7 \%$ BSA in water, and appropriate volumes assayed for I-PTH. PTH recovery during all these procedures was similar in normal (80 \pm $14.26 ; n=5)$ and in nephrectomized $(89.6 \pm 9.34 ; n=$ 5 ) rats and was calculated by dividing the total amount of I-PTH recovered in the HPLC run by the total amount of I-PTH in the processed serum $\times 100$. hPTH(1-84) and hPTH(7-84) (Bachem) processed in rat serum, as described, eluted as single peaks at the expected positions, demonstrating no degradation during the above procedures.

\section{Secretion of PTH by parathyroid cells from human parathyroid adenomas}

Experimental protocol Parathyroid tissue (230$500 \mathrm{mg}$ ) was obtained from 5 parathyroid adenomas in patients operated on for primary hyperparathyroidism. Blood was also obtained from 10 similar patients prior to surgery to study I-PTH molecular forms present in the circulation. All these patients were hypercalcemic (mean total calcium of $2.79 \pm 0.31 \mathrm{mmol} / \mathrm{l}$; normal value $=2.2-2.5 \mathrm{mmol} / \mathrm{l}$ ) and had elevated levels of I-PTH $(36.2 \pm 52.5 \mathrm{pmol} / \mathrm{l}$; range $6.4-$ $136 \mathrm{pmol} / \mathrm{l}$; normal value $=1.2-6.2 \mathrm{pmol} / \mathrm{l})$. The use of serum or tissue for research purposes was approved by the ethics committee of our center and all patients signed an informed consent.

Processing and analysis Parathyroid glands were trimmed of exogenous tissue, sliced and dispersed with collagenase-DNase, according to the method of Brown et al. $(16,17)$, at $37^{\circ} \mathrm{C}$ for $45-60 \mathrm{~min}$. The cell suspension was filtered through $200 \mu \mathrm{m}$ mesh and washed 3 times with culture medium to be described. Cell viability, assessed by the trypan blue exclusion technique, was $>95 \%$. Parathyroid cells were incubated in DMEM/F12 medium without $\mathrm{NaHCO}_{3}$ and buffered with $0.015 \mathrm{~mol} / \mathrm{l}$ HEPES, pH 7.4, 5\% FBS and $0.2 \%$ BSA at a concentration of 200000 to 300000 cells $/ \mathrm{ml}$ medium. Calcium concentration was adjusted with $\mathrm{CaCl}_{2}$ to the original patient serum calcium concentration. Secretion was studied over 1 to $2 \mathrm{~h}$ in a humidified incubator at $37^{\circ} \mathrm{C}$. After incubation, the cells were centrifuged in a pellet, and the supernatant was collected for further analysis. Storage and processing of sera and supernatants for HPLC analysis were similar to the preceding 
project in rats except that several different columns were used over the time course of these studies. Recovery of I-PTH immunoreactivity during these procedures was $103.4 \pm 17.2 \%(n=10)$. The same I-PTH assay described previously was used to analyze all HPLC profiles. A more recent cyclase activating (CA) PTH assay specific for hPTH(1-84) and non-reactive with hPTH(7-84) (18) was also used for the most recent samples.

\section{Statistical analysis}

The results are given as means \pm s.D. Comparisons were made on logarithmic concentrations by a two-way repeated measures ANOVA followed by a Tukey test. Planimetric evaluation of HPLC profiles was undertaken with Origin 4.1 software (Microcal Software, Northamton, MA, USA). Percentages of hPTH(1-84) and non-(1-84)PTH were obtained in each case and applied to total I-PTH data for proper quantitation of both molecular forms at each time point and for each rat. The same software was used to study the kinetics of hPTH(1-84) disappearance in both groups, employing a standard formula for half-life and the elimination constant $\left(K_{\mathrm{e}}\right)$. hPTH(1-84) and non-(1-84)PTH were also quantitated similarly in the serum of patients with primary hyperparathyroidism and in the supernatant of cells incubation.

\section{Results}

\section{Metabolism of hPTH(1-84) in normal and NPX rats}

Figure 1 illustrates the disappearance of injected hPTH(1-84) in normal and NPX rats. Each point represents the mean \pm S.D. for 8 rats. In both groups, I-PTH immunoreactivity decayed biexponentially with a rapid first component over the first $10 \mathrm{~min}$ and a slower second component over the rest of the study. Mean I-PTH concentrations were significantly higher at $2 \mathrm{~min}(P<0.05)$ and from 4 to $96 \mathrm{~min} \quad(P<$ $0.001)$ in NPX rats. These decay curves were separated into their components, hPTH(1-84) and non-(184)PTH, by HPLC analysis of a pool of sera at each time-point. The fractions were assayed with I-PTH, and peaks were quantitated by planimetry. This is illustrated for both groups at 8, 24 and 48 min in Fig. 2 . Only hPTH(1-84) was identified at 2 and $4 \mathrm{~min}$ at position $52 \mathrm{~min}$. Large fragments with a partially preserved N-structure were clearly identified as a shoulder to the hPTH(1-84) peak at 6 and $8 \mathrm{~min}$ at position $50 \mathrm{~min}$. Their concentration was maximal $8 \mathrm{~min}$ after the injection of $\operatorname{hPTH}(1-84)$ in both groups and higher in NPX $(92.8 \pm 13.8 \mathrm{pmol} / \mathrm{l})$ than in normal rats $(38.8 \pm 7.2 \mathrm{pmol} / \mathrm{l} ; P<0.001)$. They reached a percentage maximum at $24 \mathrm{~min}$ where they represented $40 \%$ of I-PTH immunoreactivity in both

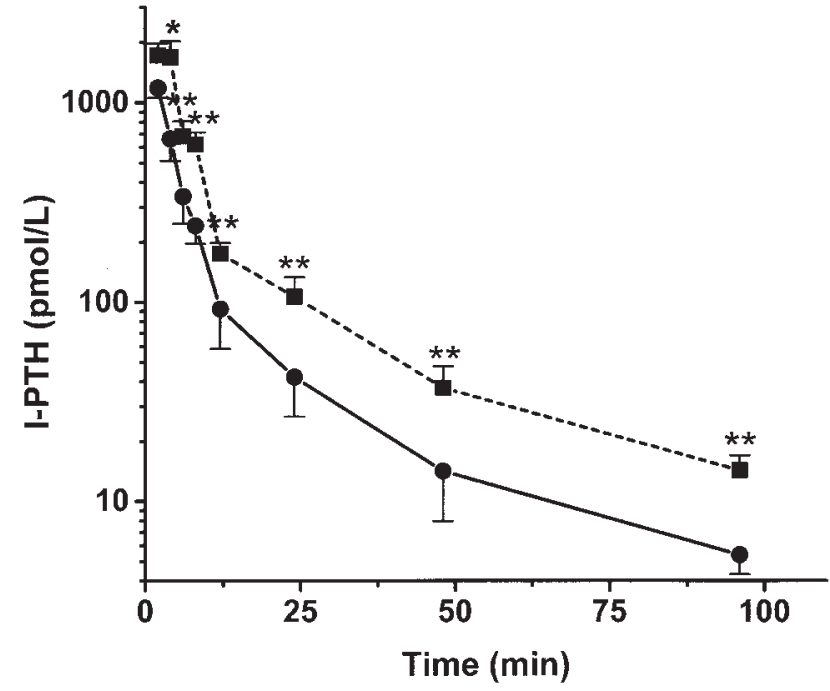

Figure 1 Decay curves of injected hPTH(1-84) in normal (๑) and nephrectomized ( $\square$ ) rats. Each point represents the mean \pm S.D. of 8 rats. Logarithmic values statistically different from normal rats by a two-way ANOVA for repeated measurements followed by a Tukey test at given time points: ${ }^{\star} P<0.05$; ${ }^{\star \star} P<0.001$.

groups. On all HPLC profiles, more fragments and hPTH(1-84) were observed in NPX rats than in normal rats. The HPLC percentages of hPTH(1-84) and fragments at each time point were next applied to individual rat values of Fig. 1 to obtain Fig. 3. The half-life of the first exponential of hPTH(1-84) decay (normal $=2.08 \mathrm{~min}$; $\mathrm{NPX}=1.94 \mathrm{~min}$ ) was similar in both groups. The half-life of the second exponential was shorter in normal $(20.9 \mathrm{~min})$ than in NPX (32.4 min) animals. This caused the residual quantity of hPTH(1-84) under the curve to be more than twice as large in NPX (6964 $\pm 2392 \mathrm{pmol})$ compared with normal rats $(3229 \pm 561 \mathrm{pmol} ; P<0.001)$. The quantity of non-(1-84)PTH under the curve was three times as large in NPX (1904 $\pm 405 \mathrm{pmol})$ than in normal rats $(664 \pm 168 \mathrm{pmol} ; P<0.001)$.

\section{Secretion of PTH by parathyroid cells from human parathyroid adenoma}

Figure 4 illustrates the HPLC profiles of immunoreactive $\mathrm{PTH}$ in the serum of patients with primary hyperparathyroidism. Ten patients were assessed by I-PTH assay, and 2 peaks were identified in all patients with 3 peaks in some patients. The major peak, at position $52 \mathrm{~min}$, co-migrated with $\mathrm{hPTH}(1-84)$ and represented $67.8 \pm 1.4 \%$ of the immunoreactivity. The second peak migrated slightly in front of hPTH(1-84) at positions $48-50 \mathrm{~min}$ and represented $27.7 \pm 1.8 \%$ of I-PTH immunoreactivity. This peak migrated similarly to non-(1-84)PTH, identified during the peripheral metabolism of hPTH(1-84) in rats, and was not recognized by the CA-PTH assay. A third minor peak was 

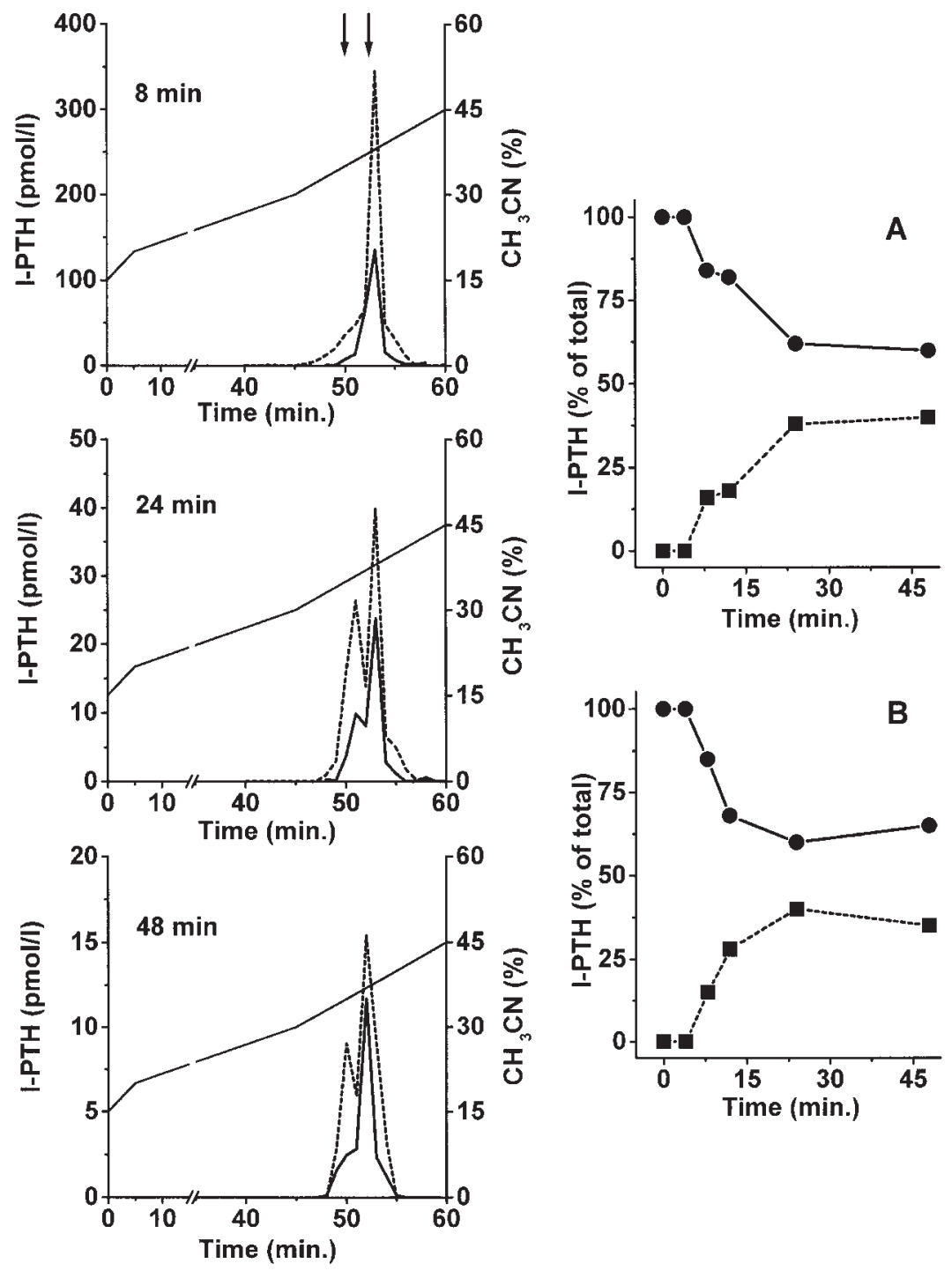

Figure 2 HPLC profiles (left) of circulating PTH in normal (solid line) and nephrectomized (dashed line) rats at 8,24 and $48 \mathrm{~min}$ after the injection of hPTH(1-84). The diagonal lines illustrate the acetonitrile $\left(\mathrm{CH}_{3} \mathrm{CN}\right)$ gradient. The respective elution positions of hPTH(7-84) and hPTH(1-84) are indicated by arrows from left to right. Planimetric analysis (right) of HPLC peaks at each time point for normal (A) and nephrectomized (B) rats. Data are expressed as percentage of total I-PTH immunoreactivity measured for hPTH(1-84)

$(\bullet)$ and recognized fragments ( $\square)$ in the 2 groups.

also present in front of the last one, at positions $42-46$ min, mainly in patients with higher basal PTH levels; it represented $4.5 \pm 1.7 \%$ of immunoreactivity and was not recognized by the CA-PTH assay. Figure 5 illustrates similar results for supernatants of parathyroid cells obtained from parathyroid adenomas. Again, with the I-PTH assay 3 peaks were identified. Within one position, these peaks eluted similarly to those described for serum and represented, respectively: position $52 \mathrm{~min}, 78.9 \pm 4 \%$, position $48-50 \mathrm{~min}$, $18.2 \pm 3.8 \%$, and position $42-46 \mathrm{~min}, 2.9 \pm 0.6 \%$. The latter two peaks were not recognized by the CA-PTH assay. The amount of fragments identified in cell supernatants was significantly less than the amount observed in serum $(21.1 \pm 3.9$ vs $32.5 \pm 1.3 ; P<0.001)$. When synthetic $\mathrm{hPTH}(1-84)$ was processed in hypoparathyroid serum, a single peak, migrating at position $52 \mathrm{~min}$, was identified.

\section{Discussion}

This study was designed to examine the origin of non-(184)PTH, large C-fragments of PTH with a partially preserved N-structure (1-3). These fragments could theoretically activate the protein kinase-C domain of the classical PTH/PTH related peptide receptor (19-23), modulate hPTH(1-84) biological effects $(7,8,23)$ or react with the less well-defined C-PTH receptor (24-27).

To study the origin of these fragments, we used different experimental models. Rats, either normal or NPX, have been used extensively to understand the metabolism of various PTH(1-84) preparations $(9,10,28,29)$, and they still appear to be the best model to examine the generation of fragments from injected hPTH(184). Rats were injected intravenously with $1.5 \mu \mathrm{g}$ $\mathrm{hPTH}(1-84)$ and we have demonstrated previously that this dose does not saturate the hepatic extraction 

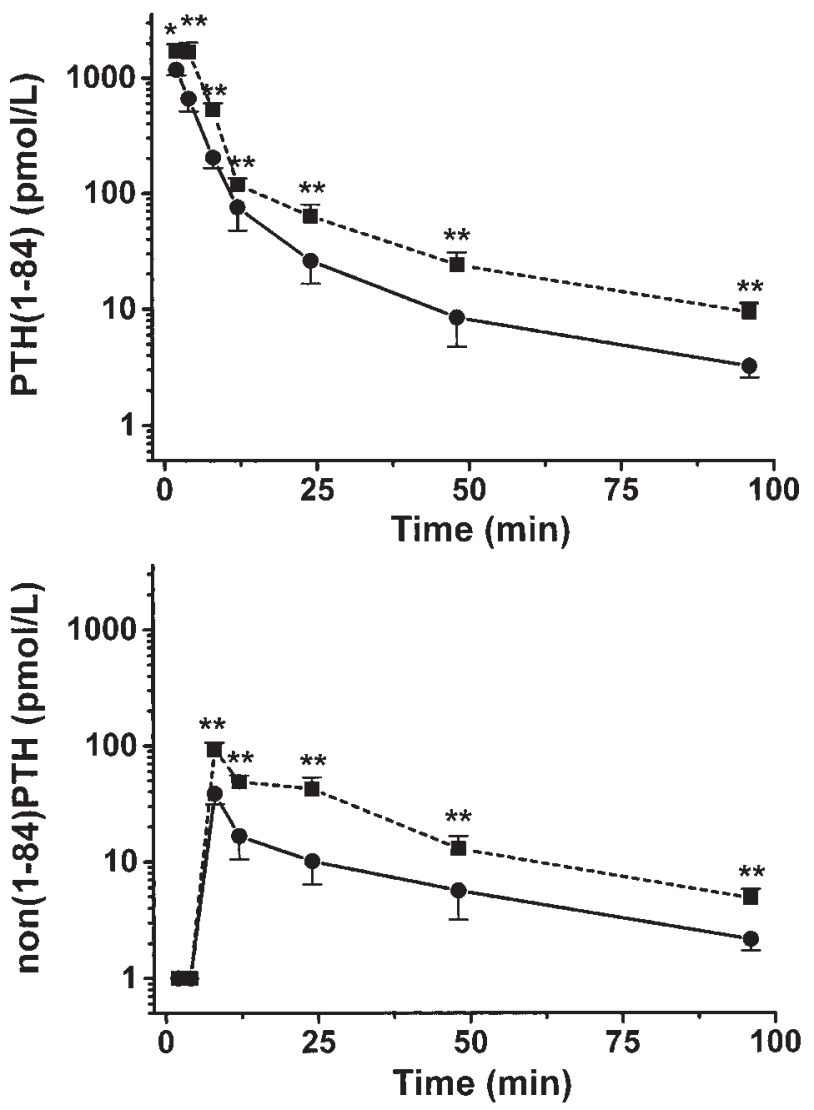

Figure 3 Application of the planimetric analysis result at each time point (from Fig. 2) to circulating I-PTH levels at the same time point (from Fig. 1) in normal $(\bullet)$ and nephrectomized (ם) rats. Results are means \pm S.D. The fate of $\mathrm{hPTH}(1-84)$ and of non-(1-84)PTH is shown. Values of normal and NPX rats were analyzed using a logarithmic transformation of the data and a two-way ANOVA for repeated measurements followed by a Tukey test: ${ }^{\star} P<0.05 ;{ }^{* \star} P<0.001$.

of PTH(1-84) (30). Parathyroid adenomas obtained at surgery have also been used to study the secretion of C-PTH fragments by the parathyroid glands $(11,12)$. To ensure that the glandular secretory products were relevant to those found in the circulation, we also looked at circulating molecular forms of PTH in patients with primary hyperparathyroidism.

Intravenously (i.v.) injected hPTH(1-84), like other PTH preparations injected i.v. into rats $(9,10,28$, 29), disappeared from serum biexponentially, first with a rapid and then with a second slower component. As expected, more I-PTH immunoreactivity was present in serum at each time point in NPX animals, reflecting decreased clearance in the absence of the kidneys $(28,29)$. This has been observed in prior studies dealing with the peripheral metabolism of ${ }^{125} \mathrm{I}-$ bPTH(1-84) or ${ }^{125} \mathrm{I}-\mathrm{bPTH}(39-84)$ (9, 10, 28, 29). HPLC fractionation of total I-PTH, at each time point, disclosed exclusively $\mathrm{hPTH}(1-84)$ at the 2 earliest time points, and a second peak in front of hPTH(1-84) at all other time points. This second peak first appeared as a shoulder to $\mathrm{hPTH}(1-84)$ at 6 and $8 \mathrm{~min}$, and as a distinct peak later on, with maximum percentage expression at $24 \mathrm{~min}$ where it represented $40 \%$ of total I-PTH immunoreactivity in both groups of rats. This is similar to what has been described for ${ }^{125} \mathrm{I} C$ fragments of ${ }^{125} \mathrm{I}-\mathrm{bPTH}(1-84)$ in normal and NPX rats $(9,10,28,29)$. The elution positions of this fragment peak and of hPTH(1-84) in rats were also similar to our findings in humans $(1-3)$. The application of HPLC planimetric data to total I-PTH values permitted us to construct a true disappearance curve for hPTH(184 ) and a mixed curve (generation + clearance) for non-(1-84)PTH. Kinetic analysis of hPTH(1-84) disclosed a similar half-life for early exponential decay in both groups, but a longer half-life for the second component in NPX animals. Again, this is similar to prior reports $(28,29)$, with the exception of a shorter halflife for the second component in both groups in our study. The difference from prior results is probably best explained by the fact that the hPTH(1-84) preparation used here was biologically active while the ${ }^{125} \mathrm{I}-\mathrm{bPTH}(1-84)$ used previously was not $(9,10,29$, 30) because of chloramine-T iodination. Prior studies have demonstrated a slightly different tissue distribution (more in the liver, less in the kidneys) of bioactive ${ }^{125} \mathrm{I}-\mathrm{bPTH}(1-84) \quad(31)$ and of bioactive internally labeled bPTH(1-84) with a somehow shorter half-life (32). Finally, more PTH fragments were observed in NPX rats at all time points, reflecting the absence of kidney clearance and increased production in the presence of more available substrate. Again, this is similar to what has been described for other C-fragments of PTH $(28,29)$ which are produced by the liver. In the end, one may wonder why non-(184)PTH was not identified previously in experiments dealing with the metabolism of ${ }^{125} \mathrm{I}-\mathrm{bPTH}(1-84)$ or internally labeled bPTH(1-84). In the first case, gel chromatography was used and was probably unable to separate these large ${ }^{125} \mathrm{I}-\mathrm{PTH}$ fragments from ${ }^{125} \mathrm{I}$ bPTH(1-84), and/or ${ }^{125}$ I-PTH fragments were not sequenced long enough to identify ${ }^{125} \mathrm{I}-\operatorname{non}(1-84)$ PTH $(9,10,29)$. In the second case (32), HPLC was performed on gel chromatography fractions and not on untouched samples, leading to the same conclusion.

The second part of our study dealt with the secretion of non-(1-84)PTH by parathyroid adenomas. The HPLC profiles of PTH in sera from 10 patients with primary hyperparathyroidism were first investigated to make sure that parathyroid gland secretory products were compatible with the circulating PTH molecular forms. hPTH(1-84) and a fragment peak corresponding to circulating non(1-84) PTH were identified in all patients and a third fragment peak, not identified before, was also seen in some patient sera. These 3 peaks were also identified as secretory products of parathyroid cell incubations. The smaller third peak was more apparent when high PTH levels were used for HPLC. These non-(1-84)PTH peaks represented $32.5 \%$ of the 

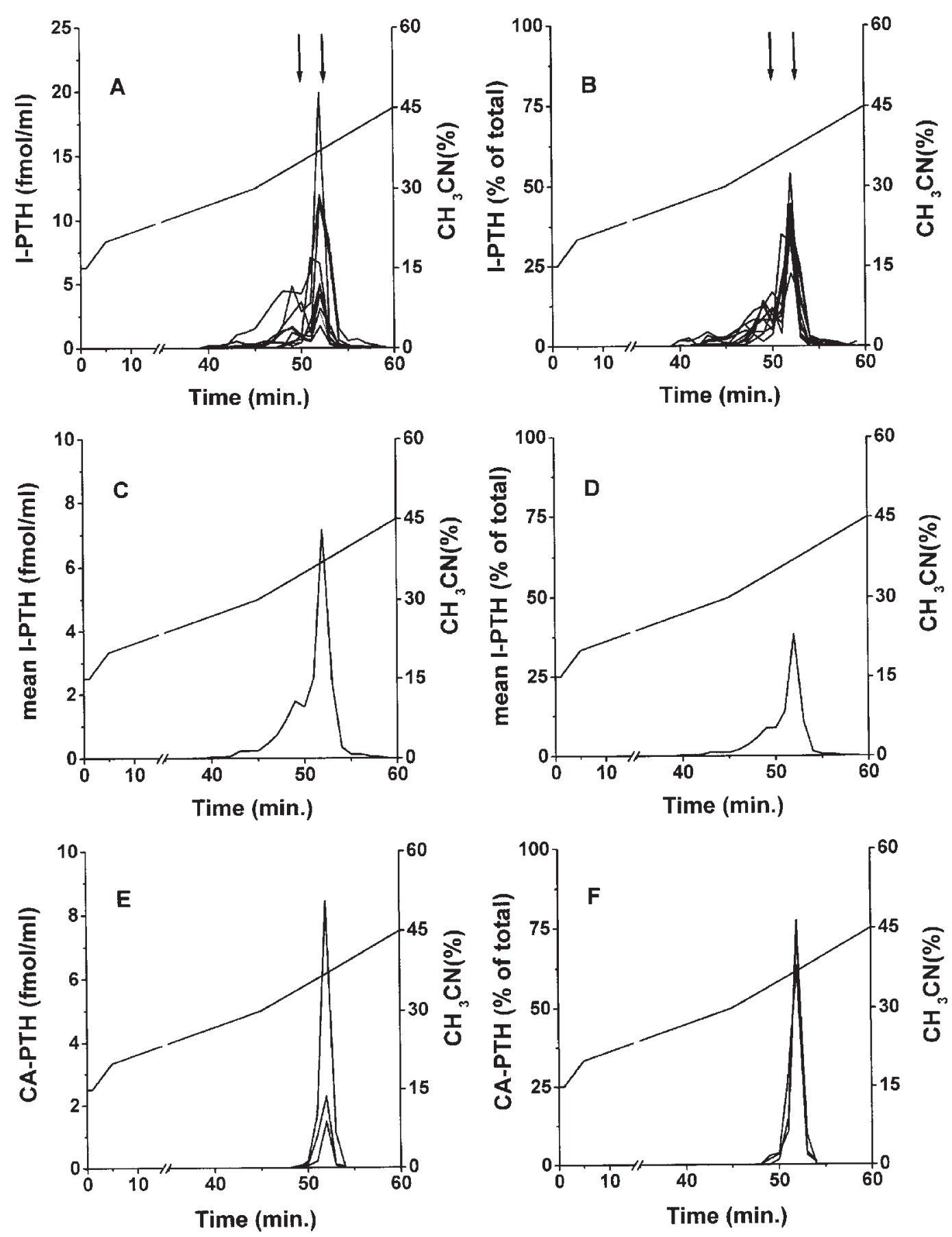

Figure 4 HPLC profiles of I-PTH and of CA-PTH present in serum of patients with primary hyperparathyroidism. Arrows indicate the elution positions of $\mathrm{hPTH}(7-84)$ and $\mathrm{hPTH}(1-84)$ from left to right respectively. The diagonal lines illustrate the acetonitrile $\left(\mathrm{CH}_{3} \mathrm{CN}\right)$ gradient. Results are expressed as absolute values on the left $(A, C, E)$ and as a percentage of total immunoreactivity on the right (B, $D, F)$. Ten profiles were analyzed with the I-PTH assay (A, B) and the mean of these results is illustrated (C, D). Three of these profiles were also analyzed with the CA-PTH assay (E, F). hPTH(1-84) and 2 more fragment peaks were recognized by the I-PTH assay in serum $(A, B, C, D)$ but only $h P T H(1-84)$ was recognized by the CA-PTH assay $(E, F)$.

immunoreactivity in serum, slightly more than in normal individuals $(1-3)$, but less than what is seen in advanced renal failure $(2,3)$. They also represented $21.1 \%$ of parathyroid gland secretory products. These peaks were not recognized by the CA-PTH assay indicating loss of the first amino acids of the PTH structure. Thus, like other C-fragments, non-(1-84)PTH is also secreted by the parathyroid glands $(11-14)$. The 

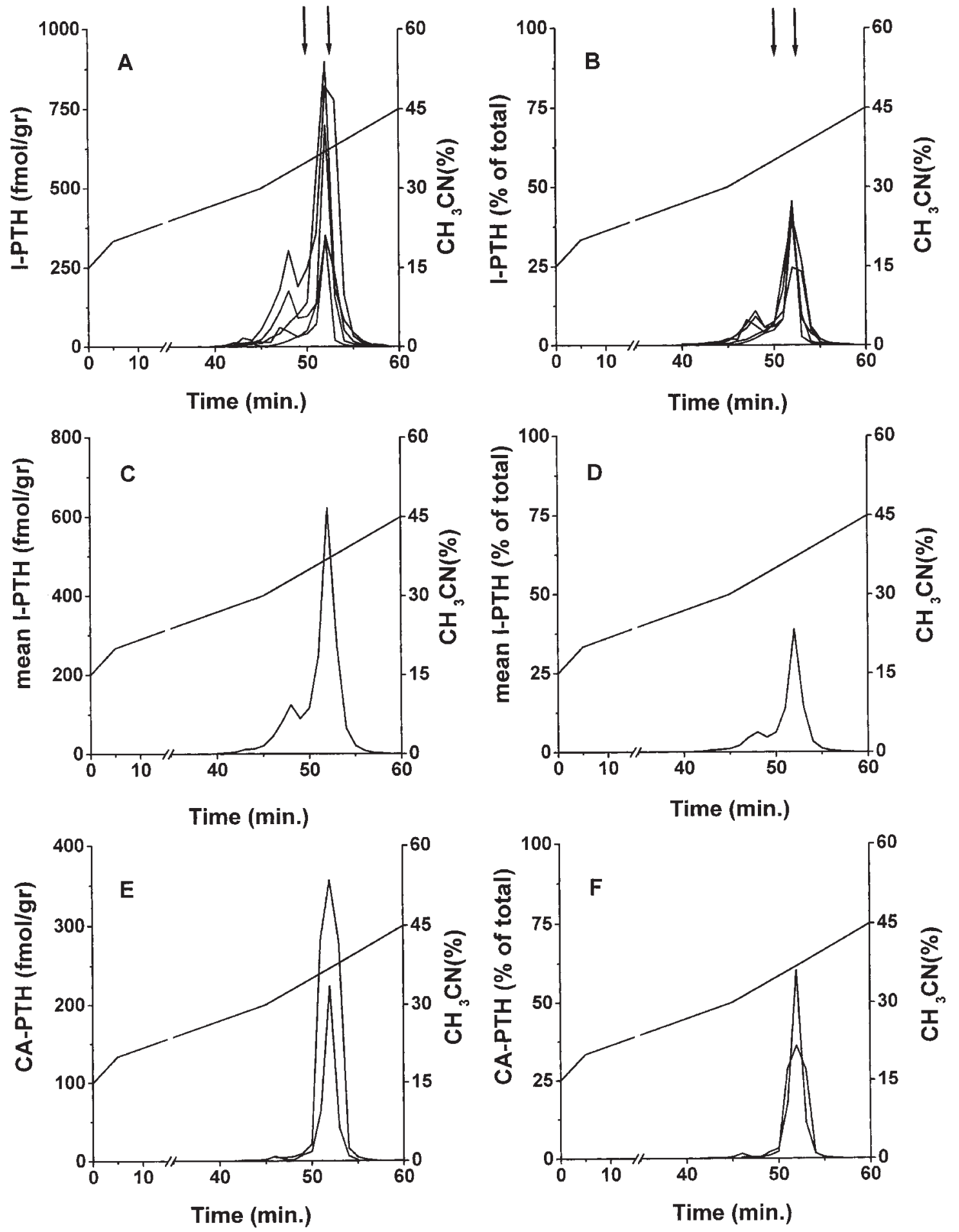

Figure 5 HPLC profiles of I-PTH present in the supernatant of parathyroid cells from parathyroid adenomas studied over $2 \mathrm{~h}$. Arrows indicate the elution positions of $\mathrm{hPTH}(7-84)$ and $\mathrm{hPTH}(1-84)$ from left to right respectively. The diagonal lines illustrate the acetonitrile $\left(\mathrm{CH}_{3} \mathrm{CN}\right)$ gradient. Results are expressed as absolute values on the left $(\mathrm{A}, \mathrm{C}, \mathrm{E})$ and as a percentage of total immunoreactivity on the right (B, D, F). Five profiles were analyzed with the I-PTH assay (A, B) and the mean of these results is illustrated (C, D). Two of these profiles were also analyzed with the CA-PTH assay (E, F). hPTH(1-84) and 2 more fragment peaks were recognized by the I-PTH assay but only $\mathrm{hPTH}(1-84)$ was recognized with the CA-PTH assay. 
higher proportion of non-(1-84)PTH in sera than in cell supernatants reflects both the longer half-life of C-fragments in serum relative to hPTH(1-84) (28) and the contribution of peripheral metabolism to circulating non-(1-84)PTH. Earlier studies (14, 33, 34), performed with porcine, bovine and human parathyroid cells, indicated that apart from fragments starting at positions 34, 37 and 43, these glands also secreted fragments starting at positions 24 and 28. These two secreted products could contribute to what we describe as non-(1-84)PTH HPLC peaks.

In conclusion, we can say that non-(1-84)PTH, like other C-fragments of PTH, has a dual origin from both the peripheral metabolism of hPTH(1-84) and the secretory process of parathyroid cells.

In renal failure, more non-(1-84)PTH is observed in relation to the decreased renal clearance of these and other C-fragments. These findings in renal failure may be important to explain PTH resistance in that situation $(7,8)$. Our results, as far as metabolism is concerned, were obtained in rats and we must assume that similar metabolism occurs in humans. The precise identity of non-(1-84)PTH remains uncertain, and more studies will be required to elucidate non-(1-84)PTH structure.

\section{Acknowledgements}

This study was supported by grant MOP-7643 from the Canadian Institutes of Health Research. The authors thank Manon Livernois for typing this manuscript and Ovid Da Silva, Éditeur/Rédacteur of the Research Support Office, CHUM Research Center, for editing it.

\section{References}

1 Brossard JH, Whittom S, Lepage R \& D'Amour P. Carboxylterminal fragments of parathyroid hormone are not secreted preferentially in primary hyperparathyroidism as they are in other hypercalcemic conditions. Journal of Clinical Endocrinology and Metabolism $1993 \mathbf{7 7} 413-419$.

2 Brossard JH, Cloutier M, Roy L, Lepage R, Gascon-Barré M \& D'Amour P. Accumulation of a non-(1-84) molecular form of parathyroid hormone (PTH) detected by intact PTH assay in renal failure: importance in the interpretation of PTH values. Journal of Clinical Endocrinology and Metabolism $1996 \mathbf{8 1}$ 3923-3929.

3 Lepage R, Roy L, Brossard JH, Rousseau L, Dorais C, Lazure C \& D'Amour P. A non-(1-84) circulating parathyroid hormone (PTH) fragment interferes significantly with intact PTH commercial assay measurements in uremic samples. Clinical Chemistry $199844805-809$.

4 Nussbaum SR, Zahradnik RJ, Lavine JR, Brennan GL, NozawaUng K, Kim LY et al. Highly sensitive two-site immunoradiometric assay of parathyrin, and its clinical utility in evaluating patients with hypercalcemia. Clinical Chemistry 198733 1364-1367.

5 Ratcliffe WA, Heath DA, Ryan M \& Jones SR. Performance and diagnostic application of a two-site immunoradiometric assay for parathyrin in serum. Clinical Chemistry 198935 1957-1961.

6 Segre GV, Tregear G \& Potts JR Jr. Development and application of sequence-specific radioimmunoassays for analysis of the metabolism of parathyroid hormone. In Methods in Enzymology, vol
XXXVII, pp 38-66. Eds BW O'Malley \& JG Hardman. New York: Academic Press, 1975.

7 Slatopolsky E, Finch J, Clay P, Marlin D, Sicard G, Singer G et al. A novel mechanism for skeletal resistance in uremia. Kidney International $2000 \mathbf{5 8} 753-761$.

8 Nguyen-Yamamoto L, Rousseau L, Brossard JH, Lepage R \& D'Amour P. Synthetic carboxyl-terminal fragments of parathyroid hormone (PTH) decrease ionized calcium concentration in rats by acting on a receptor different from the PTH/PTH-related peptide receptor. Endocrinology 2001142 1386-1392.

9 D'Amour P, Segre GV, Roth SI \& Potts JT Jr. Analysis of parathyroid hormone and its fragments in rat tissues: chemical identification and microscopical localization. Journal of Clinical Investigation 197963 89-98.

10 Segre GV, D'Amour P \& Potts JT Jr. Metabolism of radioiodinated bovine parathyroid hormone in the rat. Endocrinology 197699 $1645-1652$.

11 Flueck JA, Di Bella FP, Edis AJ, Kehrwald JM \& Arnaud CD. Immunoheterogeneity of parathyroid hormone in venous effluent serum from hyperfunctioning parathyroid glands. Journal of Clinical Investigation 197760 1367-1375.

12 Hanley DA, Takatsuki K, Sultan JM, Schneider AB \& Sherwood LM. Direct release of parathyroid hormone fragments from functioning bovine parathyroid glands in vitro. Journal of Clinical Investigation $1978 \mathbf{6 2} 1247-1254$.

13 Mayer GP, Keaton JA, Hurst JG \& Habaner JF. Effect of plasma calcium concentration on the relative proportion of hormone and carboxylterminal fragments in parathyroid venous blood. Endocrinology 1979104 1778-1784.

14 Morrissey JJ, Hamilton JW, MacGregor RR \& Cohn DV. The secretion of parathormone fragments $34-84$ and $37-84$ by dispersed porcine parathyroid cells. Endocrinology $1980 \quad 107$ $164-170$.

15 Bennett HPJ, Solomon S \& Goltzman D. Isolation and analysis of human parathyrin in parathyroid tissue and plasma. Biochemistry Journal $1981197391-400$.

16 Brown EM, Hurwitz S \& Aurbach GD. Preparation of viable isolated bovine parathyroid cells. Endocrinology $1976991582-$ 1588.

17 Brown EM, Murray FB, Hurwitz S, Windeck R, Marx SJ, Spiegel AM et al. Dispersed cells prepared from human parathyroid glands: distinct calcium sensitivity of adenomatous vs primary hyperplasia. Journal of Clinical Endocrinology and Metabolism $197846267-275$.

18 Gao P, Scheibel S, D'Amour P, John MR, Rao SD, Schmidt-Gayk H \& Cantor TL. Development of a novel immunoradiometric assay exclusively for biologically active whole parathyroid hormone 1-84: implications for improvement of accurate assessment of parathyroid function. Journal of Bone and Mineral Research 2001 16 605-614.

19 Jüppner H, Abou-Samra AB, Freeman MW, Kong XF, Schipani S, Richards J et al. A G protein-linked receptor for parathyroid hormone and parathyroid hormone-related peptide. Science 1991254 1024-1026.

20 Abou-Samra AB, Jüppner H, Force T, Freeman MW, Kong XF, Schipani E et al. Expression cloning of a common receptor for parathyroid hormone and parathyroid hormone-related peptide from rat osteoblast-like cells: a single receptor simulates intracellular accumulation of both cAMP and inositol triphosphates and increases intracellular free calcium. PNAS $1992 \mathbf{8 9}$ $2732-2736$.

21 Jouishomme H, Whitfield JF, Chakravarthy B, Durkin JP, Gagnon $\mathrm{L}$, Isaacs RJ et al. The protein kinase-C activation domain of the parathyroid hormone. Endocrinology 1992130 53-60.

22 Jouishomme H, Whifield JF, Gagnon L, MacLean S, Isaacs R, Chakravarthy B et al. Further definition of the protein kinase C activation domain of the parathyroid hormone. Journal of Bone and Mineral Research 19949 943-949.

23 D'Amour P, Dorais C, Rousseau L, Roy L \& Brossard JH. Synthetic $\mathrm{hPTH}(7-84)$ enhances the cAMP response to $\mathrm{hPTH}(1-84)$ in 
dexamethasone-treated ROS 17/28 clonal cells. Journal of Bone and Mineral Research 199712318 (abstract F369).

24 Inomata N, Akiyama M, Kubota N \& Jüppner H. Characterization of a novel PTH-receptor with specificity for the carboxylterminal region of PTH(1-84). Endocrinology $19951364732-4740$.

25 Orloff JJ \& Stewart AF. The carboxy-terminus of parathyroid hormone - inert or invaluable? Endocrinology 1995136 $4729-4731$.

26 Takasu H, Baba H, Inomata N, Uchiyama Y, Kubota N, Kumaki K et al. The 69-84 amino acid region of the parathyroid hormone molecule is essential for the interaction of the hormone with the binding sites with carboxyl-terminal specificity. Endocrinology $19961375537-5543$.

27 Murray TM, Rao LG \& Rizzoli RE. Interactions of parathyroid hormone, parathyroid hormone related-protein, and their fragments with conventional and non conventional receptor sites. In The Parathyroids, pp 195-211. Eds JP Bilezikian, MA Levine \& R Marcus. New York: Raven Press, 1994.

28 D'Amour P, Lazure C \& Labelle F. Metabolism of radioiodination carboxylterminal fragments of bovine parathyroid hormone in normal and anephric rats. Endocrinology $1985117127-134$.

29 Segre GV, D'Amour P, Hultman A \& Potts JT Jr. Effects of hepatectomy, nephrectomy and nephrectomy/uremia on the metabolism of parathyroid hormone in the rat. Journal of Clinical Investigation $198167439-448$.
30 D'Amour P \& Huet PM. Evidence of two forms of hepatic extraction of parathyroid hormone in dogs in vivo. American Journal of Physiology 1984246 E-249-E-255.

31 Teitelbaum AP, Schneider N \& Neuman WF. On the relation between peripheral cleavage of parathyroid hormone and its biological activity in kidney. Metabolic Bone Diseases Related Research $1979225-31$.

32 Bringhurst FR, Stern AM, Yotts M, Mizrahi N, Segre GV \& Potts JT Jr. Peripheral metabolism of PTH: fate of the biologically active amino terminus in vivo. American Journal of Physiology 1988 255 E886-E893.

33 MacGregor RR, Jilkoo RI \& Hamilton JW. Formation and secretion of fragments of parathormone. Journal of Biological Chemistry $19862611929-1934$.

34 MacGregor RR, McGregor DH, Lee SH \& Hamilton JW. Structural analyzed parathyroid fragments elaborated by cells cultured from a hyperplastic human parathyroid gland. Bone and Mineral 1985 1 41-50.

Received 29 October 2001

Accepted 10 April 2002 